\title{
КОНТЕКСТНЫЕ МАРКЕРЫ ВРЕМЕНИ
}

\author{
НАТАЛИЯ ГРУШИНА \\ NATALIA GRUSHINA \\ Университет Барселоны \\ Universitat de Barcelona \\ n.grushina@ub.edu \\ ORCID: 0000-0001-9598-5954
}

\section{RESUMEN}

Целью данной статьи является изучение раздичных языковых репрезентаций времени в языке и тексте. Время - абстрактная категория, прочно связанная с жизнью человека, его можно рассматривать как четвертое измерение реальности, используемое для описания событий в трехмерном пространстве. Время изучалось с разных точек зрения и в разных аспектах. Восприятие времени может варьироваться в зависимости от социальной и культурной среды. Вот почему так важно при изучении иностранного языка уделять особое внимание разнообразию представлений времени. В статье мы исследуем раздичные временные маркеры, представленные в русском языке: языковые маркеры времени, выявленные на базе словарных толкований, и контекстные временные маркеры, которые мы можем найти в неадаптированных современных текстах, используемых для упражнений на понимание прочитанного на продвинутом уровне при изучении русского как иностранного. Мы сравниваем языковые и контекстные временные маркеры, исподьзуя когнитивный подход к текстовым единицам. В качестве примера мы исподьзуем временные маркеры из текстов, опубликованных в популярном российском литературном журнале «Новый мир» на рубеже 21 века. «Новый мир» очень известен в России своей неизменной либеральной позицией и большой историей диссидентского движения.

КЛЮчЕВЫЕ СЛОВА: концепт времени, временные маркеры, текст и дискурс, когнитивная Аингвистика.

\section{CONTEXTUAL TIME MARKERS}

\section{ABSTRACT}

The aim of this paper is to study different time representations in language and text. Time is an abstract category strongly connected to human life, it can be considered to be the fourth dimension of reality, used to describe events in three-dimensional space. Time has been studied from different points of view and in different aspects. Perception of time can vary depending on social and cultural environment. That is why it is so important to pay special attention to a variety of time representations when studying a foreign language. In the article we study different time markers represented in language (English and Russian) and contextual time markers we can find in texts for reading comprehension activities at advanced levels when studying Russian as a foreign language. We compare language and contextual time markers using cognitive approach to text units. As an example, we take time markers from the texts published in a popular Russian literary magazine Novy mir, famous for its constant liberal position and great history of dissident movement during Soviet epoch.

KEYWORDS: concept of time, time markers, text and discourse, cognitive linguistics. 


\section{ВРЕМЯ В ЯЗЫКЕ}

Время всегда было предметом изучения разных областей знаний, таких, как история, философия, религия или естествознание. Многие мыслители на протяжении всей истории человечества по-разному концептуализировали и анализировали время. Платон, Аристотель, Святой Августин, Кант, Ньютон, Эйнштейн, Шпенглер, Вернадский, Бергсон и многие другие философы и ученые изучади природу времени, его физические и психодогические аспекты. Время - одно из основных понятий, связанных с восприятием реальности. Нас интересует его отражение в языке, ведь именно язык является средством структурирования, представления и концептуализации времени. В этой части мы рассмотрим раздичные определения слова «время», которое мы можем назвать системными, то есть принадлежащими языку как системе и представленными в академических языковых словарях. Важно понимать, что когда мы говорим о времени, мы имеем в виду разные идеи. Наше восприятие времени может варьироваться в зависимости от нашей культурной среды и отражается в языке, на котором мы говорим. Так, например, в русском языке все значения слова время, представленные в Большом толковом словаре (Большой Толковый словарь 1998), разделены на четыре общих определения. Время это:

1. Основная (наряду с пространством) форма существования бесконечно развивающейся материи. Бесконечность пространства и времени

2. Отрезок, промежуток в последовательной смене минут, часов, дней, лет и т.п. Отрезок времени. На короткое в. Уделять много времени учёбе.

3. Период, эпоха (в жизни человечества, какого-л. народа, государства, общества и т.п.). Военное время. Былые времена.

4. Грамм. Категория глагола, относящая действие посредством специальных форм в план настоящего, прошлого или будущего. Глаголь изменяются по временам. Образовать причастие прошедшего времени.

Если мы сравним это толкование с более ранним, представленным в Словаре современного русского литературного языка (ВАС 1951), то заметим, что в словарной статье «время» представлено 8 значений этого слова: помимо философского и лингвистического значения, время понимается как длительность, промежуток времени, эпоха, досуг, счастье, погода. Мы видим, что значение слова в русском языке развивается по пути унификации, устаревают одни значения, например, счастье, погода, переосмысляются другие например, досуг. Для сравнения, в английском языке словарь Вебстера (Webster 2019) дает нам уже 14 значений времени. В разных случаях слово «время» может означать: прододжительность, досуг, случай, возраст, время жизни, время года, темп, ритм и поворот. Может 
использоваться как существительное, глагол и прилагательное. Помимо этих значений, в английском языке существует особая форма слова для обозначения времени как грамматической категории, то есть грамматическая категория мыслится вне значения слова время, а само это понятие в английском языке представлено более дробно и мозаично.

\section{МАРКЕРЫ ВРЕМЕНИ В ЯЗЫКЕ}

Когда мы говорим о языковых маркерах времени, мы, в первую очередь, имеем в виду лексические единицы, зафиксированные словарями. Мы можем найти лексические маркеры времени, извлекая их из определения слова время. Например, из русского определения мы извлекли следующие синонимы: последовательность, мера длительности, смена, отрезок, промежуток, досуг, пора, период, эпоха. Кроме этого, в словарной статье присутствуют лексические маркеры со значением признака протекания действия: первоначально, однажды, в то же время, скоро, постоянно, вначале, своевременно, временно. В словаре синонимов русского языка в разделе время указываются: пора, эпоха, период, срок, промежуток времени, сезон, век; эра, дата. Горячее время, страдная пора. Эпоха великих реформ. Тяжкая была година. В старинны годы люди были совсем не те, что в наши дни. Лерм. Прочесть книгу в один присест. Время идет, бежит, летит, пльвет, проходит, не ждет. Время промчалось быстро. Год минул, исполнился, прошел. Ему другой годок пошел. Годков пять перепало. Обращает на себя внимание, что синонимия связана со словарным значением «период времени».

Затем мы можем упомянуть морфологические маркеры времени: грамматическое время и вид (например, Mithun 2019). Время и вид - это грамматические категории, где наиболее распространенным ориентиром является момент речи. Таким образом, мы можем разделить все события на прошлые для ситуаций до момента речи, на настоящие для тех, которые совпадают с моментом речи, и на будущие для тех, которые следуют за моментом речи. В некоторых работах (например, Allwood 2003), посвященных изучению времени в языке, среди дингвистических средств выражения времени упоминаются: повторы (например, он бегал, бегал и бегал, чтобы выразить, что процесс растягивается во времени); интонация (например, удлинение гласных для обозначения длительности); и даже жесты, такие, как быстрые движения, чтобы показать, что что-то происходит быстро. Строго говоря, маркеры времени можно разделить на лингвистические, то есть лексические (существительные и наречия времени), грамматические (глаголы), фонетические (поскольку интонация явдяется частью фонетики), синтаксические (повторы и другие средства синтаксиса) и экстрадингвистические (язык тела, жесты). Как видно из вышеизложенного, в словарях и грамматиках отражены только иексические и грамматические временные маркеры, которые могут быть легко поняты 
студентами, изучающими иностранный язык (в настоящей статье мы имеем в виду студентов, изучающих русский язык как иностранный). Другие упомянутые выше временные маркеры могут быть представлены в контексте, то есть их понимание и интерпретация могут быть затруднены для иностранных учащихся. Чтобы избежать подобных трудностей, мы рассмотрели временные маркеры в современной русской литературе и периодике и представдяем результаты в данной статье.

\section{ВРЕМЯ В КОНТЕКСТЕ}

В этой части мы сравниваем дингвистические и контекстные маркеры времени. Другими словами, мы связываем язык как структуру и познание. Такой подход возможен в рамках когнитивной дингвистики. Явдяясь частью целого комплекса когнитивных наук, когнитивная дингвистика изучает процессы и механизмы извлечения, хранения и передачи знаний посредством языка. Когнитивная дингвистика пытается ответить на вопрос, как именно человек воспринимает действительность, какие объективные и субъективные факторы участвуют в формировании видения мира той или иной этнической группой. Каждый текст читается человеком со своим менталитетом, видением реальности и дингвистической картиной мира. Таким образом, каждый текст существует как структура и как дискурс, то есть как текст со множеством экстрадингвистических факторов: особых смыслов, значений, ассоциаций, идей, связанных с ним в процессе (1) создания и (2) интерпретации / прочтения текста. Изучение дискурса позволяет рассматривать текст с точки зрения психических процессов и в связи с экстрадингвистическими факторами. Такой подход позводяет идентифицировать новые актуальные смыслы и значения, не зафиксированные в словарях и грамматиках.

Дискурсивные знания раздичаются во времени и пространстве: наше понимание и интерпретация текста, который мы читаем, зависит от нашего реального видения жизни, социальных и культурных ценностей общества, к которому мы принадлежим, и многих других факторов. Важно, чтобы когнитивные поля автора и читателей были одинаковыми или, по крайней мере, в большой мере совпадади для понимания читателем авторского текста. Как отмечали Е.М.Верещагин и В.Г.Костомаров, «коммуникация возможна при наличии некоторого общего, так называемого, фонового знания, равно присущего как адресанту, так и адресату» (Верещагин, Костомаров 1990:10). Если мы говорим о чтении на иностранном языке, мы должны быть уверены, что и текст (язык как структура), и дискурс (язык как познание) понятны учащимся. Это может быть доводьно сложной задачей при чтении неадаптированного текста на иностранном языке, потому что каждое слово в тексте получает новую жизнь; дискурс создает новую ауру или новые когнитивные подя, куда вовлекаются и, как следствие , начинают 
взаимодействовать между собой новые коннотации и новые значения слов. Конечно, это утверждение будет особенно актуадыным для значимых концептов.

Под концептом мы понимаем культурно-обусловленное и социальнозначимое понятие. Изучению концептов как кдючевых знаков культуры посвящены работы Аскольдова (Алексеева) 1997, Колесова 1999, Степанова 1997, Шмелева 2002, Вежбицкой (Wierzbicka 1999, Вежбицкая 2001) и др. Вокруг ключевых концептов сконцентрированы обширные фрагменты текста и даже целые области культуры и, конечно, понятие времени является одним из них. Мы изучили репрезентации концепта время в современной русской прозе, созданной в конце 20 - начале 21 века и опубликованной в одном из самых популярных дитературных изданий России. «Новый мир»- ежемесячный литературный журнал, известный своей диссидентской позицией, неоднозначными статьями, критикой правительства и общей либеральной ориентацией. Можно сказать, что дискурс «Нового мира» - это отражение интеллектуального состояния современного российского общества. Мы выбрали «время», потому что это понятие приобретает особое значение на рубеже веков и начала нового тысячелетия, особенно этот период был важен для России, ведь именно на этот период выпали такие яркие исторические события, как падение железного занавеса, окончание холодной войны, социально-политическая перестройка общества, падение СссР и образование новых независимый государств.

\section{КОНТЕКСТНЫЕ МАРКЕРЫ ВРЕМЕНИ}

Структура концепта аналогична ассоциативному полю слова, в которое вовлекаются связанные с ним слова и выражения. В художественных текстах это притяжение сильнее и шире из-за контекста, в котором слово начинает «жить новой жизнью». Структура концепта имеет ядерную (основную) часть и периферию. В дискурсе в концепт «время» вместе с его лексическим (словарным) значением, рассмотренным выше, втягиваются новые коннотации и дополнительные значения. Мы видим, что помимо лингвистического значения, которое мы описали выше, слово «время» приобретает новые значения и коннотации. Среди них есть следующие репрезентации:

- время как картинка (время расцвечено новыми красками)

- время как книга / текст (исторический текст времени)

- время как пространство (время как поле)

В периферийной части концепта время находятся упомянутые выше языковые маркеры времени. Но по мере развертывания дискурса в структуру концепта вовлекаются и другие части речи, семантические и синтаксические конструкции и более крупные синтаксические единицы. 
Мы можем не тодько следить за последоватедьностью событий, но и наблюдать историческое время в развитии. Другими словами, мы можем понимать текст не только как структуру, но и как дискурс, что очень важно, когда мы читаем текст на иностранном языке. В ходе развертывания повествования маркерами времени становятся не только наречия времени, но и другие лескические и синтаксические единицы, которые маркируют в тексте исторические время. Среди контекстных маркеров времени, которые мы встречали в текстах, опубликованных в журнале «Новый мир» в конце 20 - начале 21 века, наиболее часто встречадись следующие:

Имена собственные: исторические персонажи, подитики, художники, актеры, названия книг, газет, журналов, фильмов и т. Д.

Ведь в сапогах шел не любимый писатель Ольги Юрий Трифонов, которого она только что переплела, вырвав из «Нового мира». (Новый Мир 1998, 2, 17)

Солженицын к нам вернулся, Аюбимов вернулся, Войнович вернулся. Не говоря уже о не столь отдаленных по времени возвращенцах с того света - писателях Булгакове, Платонове, Цветаевой, Набокове, Манельштаме... (нм 1998, 2, 78)

\section{Топонимы, географические точки}

Ванда - спец по лекарствам, отправляет их в Союз, извиняюсь, в Россию, но не через Ольгу. (Новый Мир 1998, 2, 6).

Польша перестала быть клондайком спекулянтов, мир стал куда шире и соблазнительней. К примеру, взыграла Турция. Египет перестал быть картинкой с пирамидой. (НМ 1998, 2, 7)

\section{Социальный статус}

И пока он (Кулибин) подгонял слова к выходу, парторг сказал: - Тебе, конечно, проще. У жена тебя бэзнэсмэн. - Он так именно сказал, припадая на неправильную гласную. (Новый Мир 1998, 2, 47)

Ольга уже могла себе позводить не таскать тюки, но совсем не таскать тоже было нельзя: институт, где она была вечным мэнээсом, сгорел синим пламенем, а хотелось и то, и се... (Нм 1998, 2, 7)

\section{Реалии (предметы и материалы из повседневной жизни)}

Настраивал старенький приемник "Альпинист" на волну вещавшего до пяти утра рок-н-рольного радио, где музыка перемежалась веселым коздоглагольствованием каких-то случайных ведущих. (Новый Мир 1999, 1, 23)

В тролиейбусе красочный плакат, пропагандирующий Бхагавадгиту, изображал последовательность превращений щекастого дитяти в черноротый старческий труп. (HM 1999, 2, 50)

Прецедентные тексты иди явления (тексты, которые имеют когнитивное или эмоциональное значение, широко известные 
лингвокультурному сообществу; цитаты или ссылки на хорошо известные тексты):

\begin{abstract}
Замерев на пороге...своей квартиры, я думала, что в моей стране квартира и отдельный бачок будут посильнее "материализма и эмпириокритицизма", взятых вместе с автором. (Новый Мир 1998, 2, 30)

Неверующий человек, Кулибин боялся умереть так, чтоб там ему было стыдно за бесцельно прожитые годы. Бодрая комсомольская цитата в его мозгу имела вот такой странноватый поворот. (Новый Мир 1998, 2, 36)
\end{abstract}

Таким образом, при рассмотрении текста в качестве дискурса маркерами времени могут служить не только языковые единицы, маркированные в словарях, но и другие лексические, синтаксические и стилистические единицы, которые в ходе развертывания повествования втягиваются в сферу концепта времени.

\title{
ВРЕМЕННАЯ ПРИВЯЗКА В ЯЗЫКЕ И КОНТЕКСТЕ
}

Временная привязка в языке связана с дейксисом (от лат. отображение, демонстрация или ссылка). Дейксис - это знак, указывающий на некоторые аспекты контекста его возникновения. В случае концепта время этим знаком является момент речи или «сейчас» говорящего. Все языковые маркеры времени, которые мы упоминали ранее, организованы вокруг точки генерации текста («сейчас» говорящего). Даже когда мы говорим о внешних способах измерения времени (например, часах или календаре), оно все равно связано с говорящим и моментом его речи. Каждый говорящий делит реальное время в соответствии со своими социальными и культурными традициями и предпочтениями. Например, в русской православной церковной традиции шестое января можно назвать Сочельником, а в католицизме или других религиозных концессиях это не так. Смена времен года в России отсчитывается от первого числа календарного месяца, а в других странах отсчет ведется по астрономическому календарю, например, начало весны отсчитывается в России с 1 марта, а в странах Западной Европы - с 21 марта.

Говоря о языковых маркерах времени, мы можем видеть, что все наречия времени показывают нам точку до или после настоящего момента; вербальная грамматика также организована вокруг «сейчас» говорящего, показывая нам продолжительность, начало, продолжение, единичность или повторяемость действие, связанного с «сейчас».

В случае контекстной привязки времени у нас есть несколько дейктических точек, потому что внутри текста мы можем найти примеры (1) внешнего времени, (2) времени события (то есть хронологию событий, связанных с содержанием текста) и (3) время рассказчика (перцептивное, выражающее позицию говорящего по отношению к событиям текста). 
Точка привязки времени не фиксируется моментом формирования текста, она подвижна и может перемещаться по воле рассказчика. Маркеры времени дискурса, принадлежащие разным временным шкалам, очень часто взаимодействуют между собой. Рассмотрим несколько примеров:

Тогда недавно умер Шукшин, .... все интелдигентные люди как бы сплотились в горе. (Новый мир 1998, 2, 23)

В приведенном выше примере мы видим имя собственное, которое может быть как внешней привязкой времени (русский писатель Васидий Шукшин умер в 1974 году), так и хронологической точкой в повествовании (как указание на недавно).

Он-то уже все знает: иногородних на подготовительное не берут, тем более $\underline{c}$ Украины, которая теперь отделилась... (Новый мир 1999, 1, 20)

В данном примере маркер времени теперь относит события к настоящему времени, а упоминание об отделении Украины определяет историческое время событий: независимость страны от СССР, союзной республикой которого Украина была с декабря 1922 года, провозглашена 24 августа 1991 года.

(Родители) крутили на нем ...пару номеров "Кругозора" - журнала квадратного формата, со сквозной дыркой по центру и гибкими, как резина, прозрачными грампластинками между страниц - канувшее в Лету искдючительно отечественное изобретение. (Новый мир 1999, 2, 21)

Дейктической точкой в ходе повествования могут служить реалии, как мы видим в приведенном выше примере. Если обратимся к информации об упомянутом в тексте издании, то узнаем, что «Кругозор» - это ежемесячный советский и российский литературно-музыкальный и общественно-политический илдюстрированный журнал с аудиоприложениями в виде гибких грампластинок, который издавался в 1964-1992 годах.

Каждый раз, когда они умирали, она была в отъезде и каждый раз ее контрагенты... начинали взвинчивать цены. Отягчающими жизнь покойниками были Брежнев, Андропов и Черненко. (Новый мир 1998, 2, 40)

Имена собственные политических деятелей также служат временной привязкой повествования, по политическим событиям мы можем четко установить время действия текста, в данном случае. Это даты смерти советских лидеров: Брежнева (1982), Андропова (1984), Черненко (1985).

Кудибин... имел довольно противную привычку укдадывать... прядь волос поперек колена головы. А-ля Дукашенко, что из Белоруссии. (Новый мир 1998, 2, 35) 
В цитате мы можем найти имя собственное в описательной функции. Однако мы видим, как это же имя в рамках развертывания дискурса втягивается в сферу концепта время и начинает выступать в функции маркера времени. Интересно, что оно может относиться как ко времени рассказчика, так и к внешнему времени, поскольку Яукашенко стал известен как президент независимой Беларуси не ранее 1994 года. Здесь мы видим пример того, как дейктическая точка времени рассказчика вторгается в хронодогию событий, но не совпадает с ней.

Таким образом, временная привязка в контексте имеет более сложную структуру, чем в языке. Это следует учитывать при чтении и анадизе текста со студентами, изучающими русский язык как иностранный.

\section{Выводы}

Время - абстрактная категория, связанная с человеческой жизнью. Восприятие времени может варьироваться в зависимости от социальной или культурной среды. Вот почему так важно уделять особое внимание раздичным маркерам времени, которые мы можем найти в контексте. Эти «контекстные» временные метки могут создавать трудности для студентов, изучающих иностранный язык. В данной статье мы говорим о студентах, которые изучают русский язык как иностранный, но методы и результаты данного исследования могут быть использованы в практике преподавания иностранных языков, в при обучении чтению на иностранном языке, в курсах по переводу и исторической интерпретации текста.

\section{БИБЛИОГРАФИЯ}

AllwoOD, J. (2002), Language and Time, en Catcher of the Meaning. Publications of the Dept of General Linguistics 3, Pajusalu, R. \& Hennoste, T. (eds.), Tähendusepüüdja, University of Tartu. Available at: <https:/www.academia.edu/25321367/La nguage_and_Time> [Access date: 08/11/2020].

Mithun, M. Tense and Aspect in Morphology [online], 2019. Available at: $<$ https:/oxfordre.com/linguistics/oso/viewentry/10.1093\$002facrefore\$002f978019 9384655.001.0001\$002facrefore-9780199384655-e-548;jsessionid=9D42B889941B543 FFD672F82C017BD54> [Access date: 08/11/2020].

WEBSTER'S DictiONARY. Time [online]. Available at: <https://www.merriamwebster.com/dictionary/time? src=search-dict-box> [Access date: 08/11/2020].

WiERZBICKA, A. (1999), Emotions Across Languages and Cultures: Diversity and universals, Cambridge, Cambridge University Press.

WIKIPEDIA. Time [online]. Available at: $<$ https://en.wikipedia.org/wiki/Time\#cite_notePoidevin-7=> [Access date: 08/11/2020]. 
АскОльдОв, С. А. (1997), Конщепт и слово // Русская словесность: От теории словесности к структуре текста: Антология / Под общ. ред. В.П. Нерознака, М.: Academia, С. 267-279

БАС 1951 : Словарь современного русского литературного языка : в 17 т. Акад. наук СССР, Ин-т рус. яз. Москва ; Иенинград : Изд-во Акад. наук СССР, 1948-1965. 17 т.

Большой толковый словарь (1998), Большой толковый словарь русского языка. Гл. ред. С. А. Кузнецов. Первое издание: СПб.: Норинт [online]. Avaiable at: <http://gramota.ru/slovari/dic/?word=\%D0\%B2\%D1\%80\%D0 $\%$ B5\%D0\%BC\%D1\%8F\&all=x> [Access date: 08/11/2020].

ВЕЖБИЦКАЯ, А. (2001), Понимание культур через посредство ключевых слов, М.: Языки славянской кУльтуры.

ВЕРЕЩАГИН, Е. М., КОСТОМАРОВ, В. Г. (1990), Язык и культура. Аингвострановедение в преподавании русского языка как иностранного, М.: Русский язык.

КОАЕСОВ, В. В. (1999), «Жизнь происходит от слова...», СПб., Златоуст.

Новый мир. Ежемесячный журнал художественной литературы и общественной мысли. [online]. Available at: <http://www.nm1925.ru/> [Access date: 08/11/2020]

СЛОВАРЬ СИНОНИМОВ: Сдоварь синонимов русского языка. В2т. / Под ред А.П.Евгеньевой. Л.: Наука, 1970-71.

СТЕПАНОВ, Ю. С. (1997), Константы. Словарь русской культуры. Опыт исследования, М.: Языки славянской культуры.

ШМЕлев, А. (2002), Д Русская языковая модель мира, М.: Языки славянской культуры. 